\title{
Imaging and clinical features of Castleman Disease
}

Shuang Zhao ${ }^{1}$, Ying Wan' ${ }^{2}$ Zixing Huang ${ }^{1}$, Bin Song ${ }^{1^{*+}}$ and Jianqun $\mathrm{Yu}^{1^{* \dagger}}$ (D)

\begin{abstract}
Background: Castleman disease (CD) is a group of uncommon lymphoproliferative disorders that is easily confused with lymphoma or other solid tumors. The purpose of our study was to evaluate the imaging and clinical findings of $C D$, and thus improve the understanding and diagnosis of $C D$.

Methods: This retrospective study included 74 patients (37 men and 37 women, mean age \pm standard deviation, $35 \pm 15.2$ years, ) with histopathologically confirmed CD diagnosed based on CT or MRI between January 2010 and May 2017. The CT and MRI findings were analyzed by two radiologists in consensus, and clinical presentation and histopathologic characteristics were documented.

Results: The CD subtypes included 61 hyaline vascular variant cases (82.4\%) and 13 plasma cell variant cases (17.6\%). Unicentric CD and multicentric CD were observed in 65 (87.8\%) and 9 (12.2\%) patients, respectively. On non-enhanced $C T$, enlarged nodes with hypodensity or isodensity were seen, whereas varying degrees of enhancement were observed in contrast-enhanced CT. Homogeneous and heterogeneous enhancements were observed in 43 (62.3\%) and 26 (37.7\%) patients, respectively. Hypertrophied vessels and calcification were detected in 38 (51.2\%) and 18 (24.3\%) patients, respectively. MRI revealed hypointense to isointense lesions on T1-weighted images, isointense to hyperintense lesions on T2-weighted images, and hyperintense lesions on diffusion-weighted imaging; 9 (75\%) and 3 (25\%) patients demonstrated homogeneous and heterogeneous enhancement, respectively.

Conclusion: CD often shows well-defined, mildly hypodense or isodense, homogeneous lymph nodules on nonenhanced CT/MRI, with intermediate and marked enhancement on contrast-enhanced CT/MRI. Calcification and hypertrophied vessels may be valuable diagnostic features.
\end{abstract}

Keywords: Castleman disease, Computed tomography, Magnetic resonance imaging, Diffusion-weighted imaging

\section{Background}

Castleman disease (CD), also known as giant lymph node hyperplasia, lymphoid hamartoma, or angiofollicular lymph node hyperplasia, is a group of uncommon lymphoproliferative disorders that share common lymph node histological features. The disease was first described in a single case in 1954 [1], followed by a small series of cases in 1956 [2]. The cause of CD remains unclear; however, possible causes include chronic inflammation, lymphoid hamartomatous hyperplasia, and an increase in serum interleukin-6 levels, among others [3]. Most commonly, CD is classified clinically as unicentric

\footnotetext{
*Correspondence: songlab_radiology@163.com; cjr.yujianqun@vip.163.com ${ }^{+}$Bin Song and Jianqun Yu contributed equally to this work.

'Department of Radiology, West China Hospital, Sichuan University, No. 37, GUOXUE Alley, Chengdu 610041, China

Full list of author information is available at the end of the article
}

CD (UCD) or multicentric CD (MCD) and histologically as hyaline vascular variant (HVV) or plasma cell variant (PCV) $[3,4]$. CD occurs throughout the body on surfaces such as the chest [5], neck [6], abdomen, pelvis [7], axilla [8], and on rare occasions the lung [9], parotid gland [10], and pancreas [11].

$\mathrm{CD}$ is easily confused with lymphoma or other solid tumors. Knowledge of the imaging features of $\mathrm{CD}$ is important to ensure prompt diagnosis and treatment. However, the infrequent occurrence of $\mathrm{CD}$ has led to a limited analysis of its imaging characteristics as well as susceptibility to misdiagnosis during diagnostic imaging. Some studies have described the CT and MRI features of $\mathrm{CD}$ in various parts of the human body; however, these studies were mainly case reports, review articles, and small retrospective studies [12-16]. Hence the present

(c) The Author(s). 2019 Open Access This article is distributed under the terms of the Creative Commons Attribution 4.0 International License (http://creativecommons.org/licenses/by/4.0/), which permits unrestricted use, distribution, and 
Table 1 Summary of the Main Clinical Information in Castleman disease $(n=74)$

\begin{tabular}{|c|c|c|c|}
\hline & UCD $(n=65)$ & $\operatorname{MCD}(n=9)$ & $P$ \\
\hline Age (mean, years) & $32.2 \pm 14.8$ & $41.8 \pm 17.4$ & 0.155 \\
\hline Gender & & & 1 \\
\hline Male & $33 / 51 \%$ & $4 / 44.4 \%$ & \\
\hline Female & $32 / 49 \%$ & $5 / 55.6 \%$ & \\
\hline Pathological type & & & 0.000 \\
\hline $\mathrm{HW}$ & $60 / 92.3 \%$ & $1 / 11.1 \%$ & \\
\hline PCV & $5 / 7.7 \%$ & 8/88.9\% & \\
\hline Non-symptomatic & 56 & 0 & 0.000 \\
\hline fever & 0 & 9 & 0.000 \\
\hline cough & 9 & 9 & 0.000 \\
\hline thoracic or abdominal pain & 0 & 9 & 0.000 \\
\hline dyspnea & 0 & 8 & 0.000 \\
\hline hemoptysis & 0 & 4 & 0.000 \\
\hline B symptoms ${ }^{a}$ & 0 & 3 & 0.000 \\
\hline
\end{tabular}

retrospective study described the CT/MRI findings of CD and correlated them to its histopathologic characteristics.

\section{Materials and methods}

The institutional review board approved this retrospective study; the requirement for informed consent was waived.

\section{Subjects}

We searched the pathology database in our hospital and identified patients diagnosed with CD and treated at our hospital between January 2010 and May 2017. In addition, these patients also had a record of CT or MRI examination that was performed within 1 month before surgery or biopsy. In total, 107 patients with CD were identified, 74 (37 men and 37 women; mean age \pm SD, $35 \pm 15.2$ years,) of which had complete clinical and imaging data and were included in this study. The remaining 33 patients were excluded because of incomplete imaging data. Prior to treatment, 69 patients had CT and 12 had MRI scans; 7 patients had both CT and MRI scans. Plain and contrast-enhanced scans were acquired for all patients.

\section{Clinical manifestations}

The following pre-treatment clinical information, when available, was retrieved from the electronic medical record.

\section{Pathologic data}

All cases were diagnosed histopathologically (surgical resection or biopsy) by a lymphatic pathologist. The lesions were classified as HVV when the lymph node (LN) harbored atrophic follicles with hyalinized vessels and concentric rings of lymphocytes, and if the interfollicular cells were predominantly lymphocytes. The lesions were classified as PCV when the LN architecture was characterized by a paucity of follicular hyaline vessels and accompanied by a marked accumulation of plasma cells in the interfollicular areas [17].

\section{Imaging}

CT was performed using a 64-row MDCT scanner (Brilliance64, Philips Medical Systems) and a dual-source CT system (Somatom Definition Flash, Siemens Healthcare Sector) with the following scan parameters: voltage $=120$ $\mathrm{kV}$, amperage $=110-210 \mathrm{~mA}$, rotation time $=0.5 \mathrm{~s}$, detector collimation $=0.625 \mathrm{~mm}$, pitch $=0.8-1.0$ and section thickness $=3.0-5.0 \mathrm{~mm}$. A non-ionic contrast medium (75-100 $\mathrm{ml}$; Omnipaque 350, GE Healthcare) was intravenously injected using a power injector at a rate of $3 \mathrm{ml} / \mathrm{s}$. An enhanced scan of multiple sites was performed at our institute starting with the chest, followed by the abdomen, and

Table 2 Breakdown of involved sites in multicentric Castleman disease $(n=9)$

\begin{tabular}{|c|c|c|c|c|c|c|c|c|}
\hline Sites & Neck & Axillary & Mediastinum & Hilum & Peritoneal & Retroperitoneal & Iliac & Inguinal \\
\hline \multicolumn{9}{|l|}{ Case } \\
\hline 1 & + & + & + & - & + & + & + & + \\
\hline 2 & + & + & + & - & + & + & + & + \\
\hline 3 & + & + & + & + & - & + & - & - \\
\hline 4 & + & + & - & - & + & + & + & + \\
\hline 5 & - & + & + & - & - & - & - & - \\
\hline 6 & + & + & + & + & - & + & + & + \\
\hline 7 & + & - & - & - & - & - & - & - \\
\hline 8 & - & + & + & + & + & + & + & + \\
\hline 9 & + & + & + & + & + & - & + & + \\
\hline Total & 7 & 8 & 7 & 4 & 5 & 6 & 6 & 6 \\
\hline
\end{tabular}


finally of the neck. With the trigger threshold of the aorta reaching $100 \mathrm{HU}$, a scan of the thoracic and abdominal regions (arterial portal phase) was performed at the trigger, and the portal vein phase of the abdominal region was performed $35 \mathrm{~s}$ after the trigger; the neck region was the last to be scanned.

MRI was performed using a 1.5-T MRI scanner (Siemens Medical Solutions) using the following protocol: neck, axial T1 spin echo (TR/TE, 613/8.4 ms), axial T2 TSE (TR/TE, 6020/87.0 ms), coronal T2 TSE (TR/TE, 3000/39.0 ms), axial T1 gradient echo (TR/TE, 251/2.85 $\mathrm{ms})$, axial/coronal post-gadolinium $\mathrm{T} 1$; thorax, axial TRUFI (TR/TE, 295.81/1.16 ms), axial T2 half-Fourier acquisition single-shot TSE (TR/TE, 1000/25.0 ms), axial T2 TSE (TR/TE, 3500/74.0 ms), coronal T2 TSE (TR/ TE, 3300/71.0 ms), axial diffusion-weighted imaging (DWI) (TR/TE, 2500/68.0 ms; b value, 0,50, $600 \mathrm{~s} / \mathrm{mm}^{2}$ ), axial/coronal post-gadolinium $\mathrm{T} 1$; abdomen, axial TRUFI (TR/TE, 4.05/1.8 ms), T2 TSE (TR/TE, 2860/ $84.0 \mathrm{~ms}$ ), axial DWI (TR/TE, 2500/68.0 ms; b value, 0,50, $600 \mathrm{~s} / \mathrm{mm}^{2}$ ), in- and out-of-phase T1, pre-gadolinium and axial/coronal post-gadolinium fat-suppressed T1 VIBE (TR/TE, 5.41/2.39 ms); and pelvis, axial T1 TSE (TR/TE, 550/12.0 ms), axial/coronal T2 TSE (TR/TE, 8830/103.0 ms), sagittal TRUFI (TR/TE, 3.53/1.51 ms), axial DWI (TR/TE, 3500/73.0 ms; b value, 0, 50, 800), and axial/coronal and sagittal post-gadolinium T1 VIBE (TR/TE, 5.41/2.39 ms). All contrast-enhanced MRI examinations were performed with a gadolinium chelate administered at a dose of $0.1 \mathrm{mmol} / \mathrm{kg}$ body weight.

\section{Image analysis}

Two abdominal radiologists with 7 and 13 years of experience in imaging diagnosis reviewed the images for consensus at PACS workstations (Syngo-Imaging, version VB36A, Siemens Healthcare, Germany). The following CT features of lesions were analyzed: location, distribution, morphology, margin, longest dimension, homogeneity, calcification, degree, and pattern of enhancement, vascular invasion, hypertrophied vessels, pulmonary lesions, ascites or pleural effusion, and splenomegaly. Morphology was categorized as regular-shaped, irregular or lobulated. The longest dimension was measured in maximum cross section on the transverse axis. The degree of enhancement was categorized as hyper-, iso-, or hypo-attenuating compared to the muscles of the same level on the arterial and portal phases. Enhancement pattern was described as homogeneous and heterogeneous. Splenomegaly was defined as the longest diameter of the spleen $>12 \mathrm{~cm}$ in cross-section.

The following features were recorded on the MR images: location, distribution, morphology, margin, longest dimension, homogeneity, degree and pattern of enhancement, vascular invasion, hypertrophied vessels, pulmonary lesions, ascites or pleural effusion, splenomegaly, signal intensity relative to that of muscles on T1- and T2-weighted sequences, signal intensity on DWI and the mean ADC, and presence or absence of enhancement and its pattern.

UCD was defined as an enlargement confined to one anatomical node station, while MCD was defined as an enlargement at more than one node station or the presence of multiple enlarged, separated nodes at one node station.

Table 3 Summary of the Main Computed Tomography Findings in Castleman disease $(n=69)$

\begin{tabular}{llll}
\hline CT Findings & $\mathrm{HW}(n=57)$ & $\mathrm{PCV}(n=12)$ & $P$ \\
\hline Clinical type & & & 0.000 \\
$\quad$ Unicentric & 56 & 4 & \\
$\begin{array}{l}\text { Multicentric } \\
\text { Margin }\end{array}$ & 1 & 8 & 0.540 \\
$\quad$ & & \\
Well & 51 & 12 & \\
$\begin{array}{l}\text { Circumscribed } \\
\text { Infiltrate into the }\end{array}$ & 6 & & \\
$\begin{array}{l}\text { Surrounding } \\
\text { Longest diameter }\end{array}$ & $\begin{array}{l}5.4 \pm 2.4 \mathrm{~cm} \\
(\text { rang: } 1.5 \sim 14.0 \mathrm{~cm})\end{array}$ & $\begin{array}{l}2.6 \pm 1.7 \mathrm{~cm} \\
(\text { rang: } 1.0 \sim 10.9 \mathrm{~cm})\end{array}$ & 0.000
\end{tabular}

$\begin{array}{lll}\text { Homogeneity } & & \\ \text { Homogeneous } & 50 & 12 \\ \text { Heterogeneous } & 7 & 0 \\ \begin{array}{l}\text { Pattern of } \\ \text { enhancement }\end{array} & \\ \text { Homogeneous } & 31 & 12 \\ \text { Heterogeneous } & 26 & 0\end{array}$

Degree of 1

enhancement

Hyper--

Iso-

Hypo-

Calcifications

Punctate

Branched

Coarse

Hypertrophied

vessels

\section{Feeding artery}

Draining vein

$$
\begin{aligned}
& 26^{b} \\
& 25^{b}
\end{aligned}
$$

12

0

0

0

Splenomegaly $(n=8)^{c}$

$\begin{array}{lll}\text { Unicentric } & 1 & 1 \\ \text { Multicentric } & 0 & 6\end{array}$
$U C D$ unicentric Castleman disease, MCD multicentric Castleman disease, HVV Hyaline vascular variant; $P C V$ Plasma cell variant In four patients, the $\mathrm{CD}$ lesion presented multiple calcified areas with different patterns

${ }^{b} 13$ patients had both the hypertrophied feeding arteries and draining veins $c_{33}$ patients underwent abdominal scanning, including $24 U C D$ and $9 M C D$ 


\section{Statistical analyses}

Data were analyzed using the Statistical Analysis System (SAS) software, Version 9.4 (SAS Institute Inc.). Quantitative variables were described using mean \pm SD and categorical data using frequency and percentage in the text and figures. Kolmogorov-Smirnov tests were used to check the normality assumption. Univariate analysis was performed by using the Student's $t$-test or the MannWhitney U test. Categorical data were compared using the Chi-square test or Fisher's exact test. A value of $P<0.05$ was considered statistically significant.

\section{Results}

\section{Clinical manifestations}

The clinical characteristics of $\mathrm{CD}$ are summarized in Table 1. Most of the patients with UCD had no obvious symptoms upon admission to our hospital; however, masses were found either during a routine physical examination or due to the patient accidentally touching the tumor. All MCD patients showed obvious clinical symptoms. There was no statistical difference in sex and age at the onset between MCD patients and UCD patients. The pathological type of most UCD was HVV, whereas that for most MCD was PCV. Only four of the MCD patients were tested for HIV and their results were negative. No patient was tested for human herpesvirus $8(\mathrm{HHV}-8)$.

\section{Imaging findings}

Ct

For the 65 patients with UCD, the anatomical distribution of the affected lesions as observed through imaging was as follows: abdominal $=30$, thoracic $=22$, neck $=10$, axillary $=2$, and shoulder $=1$. Compartmental distribution of the thoracic lesions was as follows: mediastinal = 11, hilar $=10$, and cardiophrenic angle $=1$. Among the abdominal lesions, 22 and 8 were in the retroperitoneal and peritoneal reflection, respectively. For the 9 patients with MCD, the anatomical distribution of the affected lesions at each involved site is shown in Table 2.

For the patients with UCD, the mean of the longest lesion diameter was $5.5 \pm 2.4 \mathrm{~cm}$ (range, 1.5 to $14.0 \mathrm{~cm}$ ) with the lesions measuring $<5.0 \mathrm{~cm}$ in 34 patients and $\geq 5.0 \mathrm{~cm}$ in 31 patients. For the patients with MCD, the mean of the longest lesion diameter was $2.3 \pm 1.0 \mathrm{~cm}$ (range, 1.0 to $4.9 \mathrm{~cm}$ ). The lesions were significantly larger in patients with UCD than in those with MCD $(p=0.000)$.
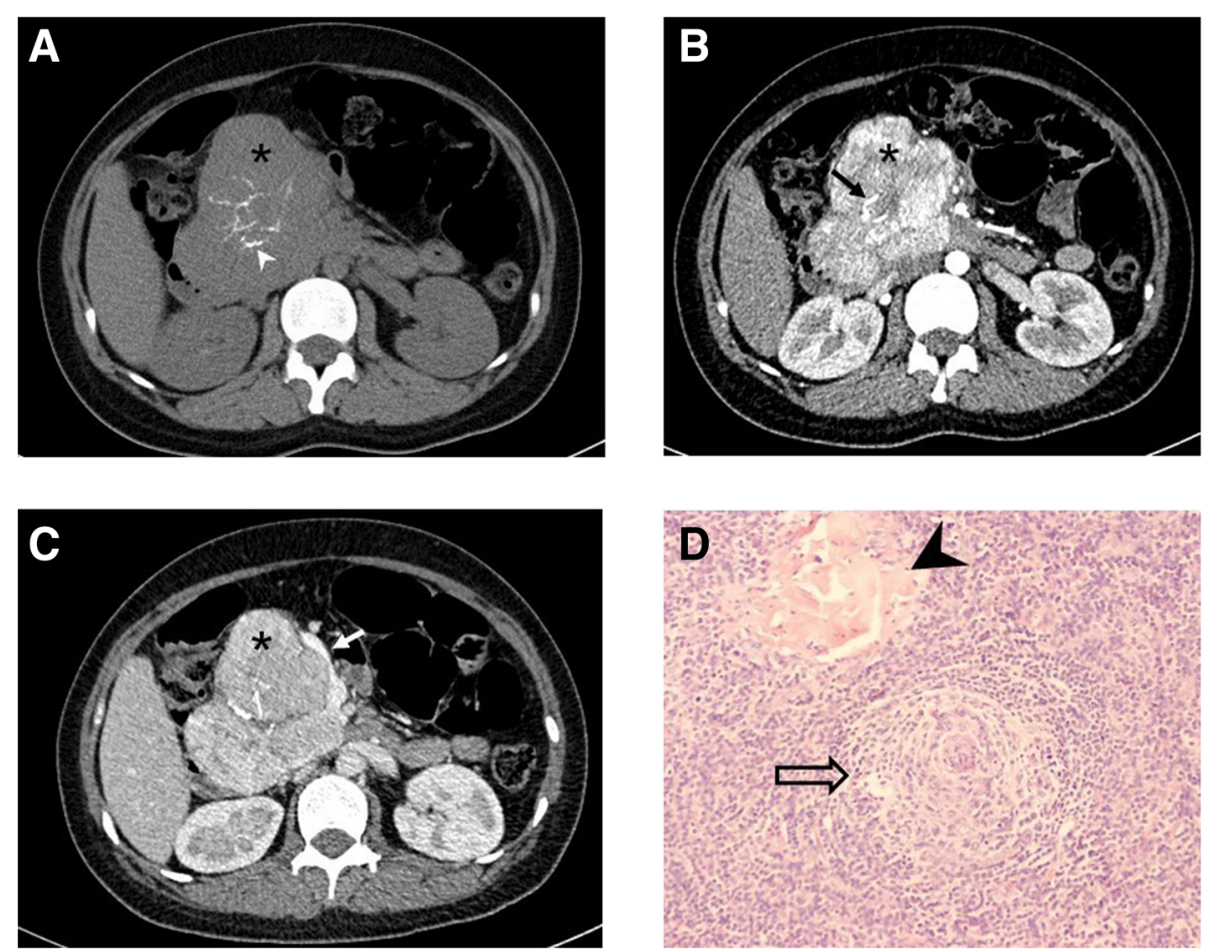

Fig. $1 \mathrm{HW}$ unicentric Castleman disease in a 26-year-old woman. Axial non-enhanced (a), arterial phase (b), and portal venous phase (c) computed tomography images of the abdomen depict a well-defined heterogeneous mass of soft-tissue density $\left(^{*}\right)$ with branched calcification at the pancreatic head (arrowhead), which shows progressive enhancement, slightly greater than that of the pancreas. The feeding artery (black arrow) and draining vein (white arrow) can be seen. Photomicrograph (d, original magnification, $\times 200$; hematoxylin-eosin [H-E] staining) shows marked vascular proliferation and hyalinization of the abnormal germinal center, with a tight concentric layering of lymphocytes at the periphery of the follicle, resulting in an "onion-skin" appearance (open arrow) and vessel-rich interfollicular stroma (arrowhead). (UCD = unicentric Castleman disease; $\mathrm{MCD}=$ multicentric Castleman disease; HW = Hyaline vascular variant; PCV = Plasma cell variant) 
The main CT findings in 69 patients with CD who underwent CT are summarized in Table 3. The morphology of all lesions was regular. On non-enhanced CT images, the lesions appeared hypodense to isodense relative to the skeletal muscle, and all PCV lesions and most HVV lesions were homogeneously dense. The enhancement pattern was homogeneous in $43(62.3 \%)$ patients, including 36 (83.7\%) with $<5.0 \mathrm{~cm}$ lesions and $7(16.3 \%)$ with $\geq 5.0 \mathrm{~cm}$ lesions. The enhancement pattern was heterogeneous in 26 (37.7\%) patients, including $17(65.4 \%)$ with $<5.0 \mathrm{~cm}$ lesions and 9 (34.6\%) with $\geq 5.0 \mathrm{~cm}$ lesions. Among the 33 patients who underwent abdominal scanning, 18 (54.5\%) and 15 (45.5\%) demonstrated peak contrast enhancement on portal or arterial phase images, respectively (Fig. 1).

The calcified lesions were distributed in the retroperitoneum $(n=9)$, mesenterium $(n=3)$, mediastinum $(n=2)$, neck $(n=2)$, pulmonary hilum $(n=1)$, and cardiophrenic angle $(n=1)$. Hypertrophied feeding arteries around the lesions were observed in 26 (35.1\%) patients (abdominal $=10$, thoracic $=9$, neck $=7$ ), while enlarged draining veins around the lesions were observed in 25 $(33.8 \%)$ patients (abdominal $=10$, thoracic $=6$ and neck $=9)$. Both hypertrophied feeding arteries and draining veins (abdominal $=4$, thoracic $=3$, neck $=6$ ) were seen in $13(17.6 \%)$ patients (Fig. 1). All patients with hypertrophied vessels were of the HVV type.

There were two patients with CD involving the lung. In one patient, multiple ground-glass opacities (GGOs), thin-walled cysts, and scattered subpleural nodules with bronchovascular bundle and interlobular septal thickening were observed (Fig. 2). In the other patient, diffuse, small nodules, interlobular septal and bronchovascular bundle thickening, and scattered GGOs were observed.

In addition, two patients with PCV (one with UCD and the other with MCD) had pleural effusion and ascites at presentation. The patient with MCD had
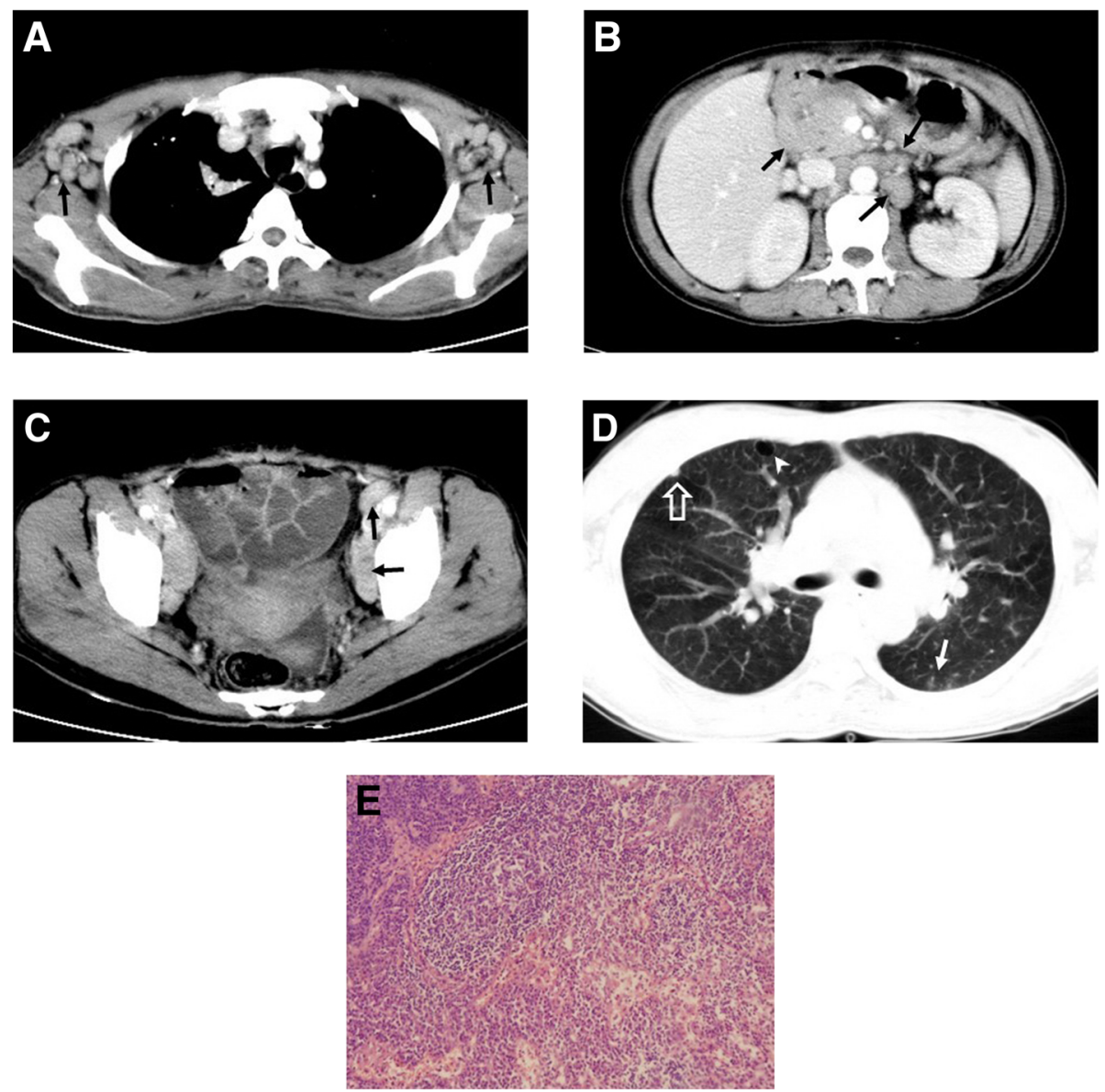

Fig. 2 A 43-year-old woman with PCV multicentric Castleman disease. Enhanced computed tomography scan shows multicentric, moderately enhancing, enlarged LNs (arrows) in the bilateral axillae (a), abdomen (b) and pelvis (c). Lung windows (d) of the CT scan shows multiple GGOs (arrow), thin-walled cysts (arrowhead), and scattered subpleural nodules (open arrow) with bronchovascular bundle and interlobular septal thickening. Photomicrograph (e, original magnification, $\times 200$; hematoxylin-eosin [H-E] stain) shows diffuse plasma cell proliferations in the interfollicular tissue. (LN = lymph node; UCD = unicentric Castleman disease; MCD = multicentric Castleman disease; HW= Hyaline vascular variant; PCV = Plasma cell variant; GGOs = Ground-glass opacities) 
moderate bilateral pleural effusion and severe ascites, whereas the patient with UCD had mild to moderate bilateral pleural effusion and ascites. No abnormal pleural thickening, nodules, or enhancement were observed.

MRI

All 12 patients who underwent MRI had UCD. The main MRI findings of CD are summarized in Table 4. The morphology of all lesions was regular and well-circumscribed. No hypertrophied vessels and splenomegaly were found in these lesions (Fig. 3).

\section{Follow-up}

There was no recurrence during the follow-up period (2476 months) after surgery in 66 patients. There were 7 patients with PCV MCD that underwent chemotherapy and remained stable $(n=3)$ or in remission $(n=4)$ during the follow-up period of 24-60 months. The patient with MCD exhibited moderate bilateral pleural effusion and severe ascites, which subsequently developed into B-cell lymphoma.

\section{Discussion}

In our study, most patients with UCD had no clinical symptoms, whereas most MCD patients had significant

Table 4 Summary of Main Magnetic Resonance Imaging Findings in Castleman disease $(n=12)$

\begin{tabular}{|c|c|c|c|}
\hline MR Findings & $\mathrm{HW}(n=10)$ & $\mathrm{PCV}(n=2)$ & $P$ \\
\hline Longest Diameter & $\begin{array}{l}5.5 \pm 1.3 \mathrm{~cm} \\
\text { (rang: } 3.7 \mathrm{~cm} \sim 7.8 \mathrm{~cm} \text { ) }\end{array}$ & $\begin{array}{l}6.6 \pm 0.3 \mathrm{~cm} \\
(6.4 \mathrm{~cm}, 6.8 \mathrm{~cm})\end{array}$ & 0.228 \\
\hline Homogeneity & & & 1 \\
\hline Homogeneous & 7 & 2 & \\
\hline Heterogeneous & 3 & 0 & \\
\hline T1 weighted & & & 1 \\
\hline isointense & 5 & 1 & \\
\hline slight hyperintense & 5 & 1 & \\
\hline T2 weighted & & & 0.167 \\
\hline isointense & 0 & 1 & \\
\hline hyperintense & 10 & 1 & \\
\hline $\begin{array}{l}\text { Enhancement } \\
\text { Pattern }\end{array}$ & & & 1 \\
\hline Homogeneous & 7 & 2 & \\
\hline Heterogeneous & 3 & 0 & \\
\hline \multicolumn{4}{|l|}{$\begin{array}{l}\text { Enhancement } \\
\text { Degree }\end{array}$} \\
\hline Hyper- & 10 & 2 & \\
\hline \multicolumn{4}{|l|}{ 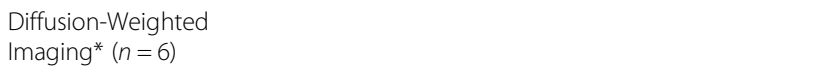 } \\
\hline $\begin{array}{l}\text { hyperintense } \\
\left(\mathrm{b}=600 \mathrm{~s} / \mathrm{mm}^{2}\right)\end{array}$ & $\begin{array}{l}5 \\
\text { (mean ADC: } 1.34 \\
\times 10^{-3} \mathrm{~mm}^{2} / \mathrm{s} \text { ) }\end{array}$ & $\begin{array}{l}1 \\
\text { (mean ADC: } \\
1.09 \times 10^{-3} \mathrm{~mm}^{2} / \mathrm{s}\end{array}$ & \\
\hline
\end{tabular}

UCD unicentric Castleman disease, $M C D$ multicentric Castleman disease, $H V V$ Hyaline vascular variant; $P C V$ Plasma cell variant *b value $=0,50,600 \mathrm{~s} / \mathrm{mm}^{2}$ clinical symptoms; most of the UCD histopathological types were HVV, while most of the MCD histopathological subtypes were PCV, similar to previous studies [4, $17,18]$. Most of the lesions encountered in our study were noninvasive masses with well-defined borders. On the non-enhanced CT images, CD classically presented slightly hypodense to isodense lesions, whereas the degree of enhancement varied on contrast-enhanced CT images. The degree of enhancement was not significantly different between the patients with HVV and those with PCV, which is similar to the findings in studies by Hill et al. [14] and Kwon et al. [19] but different from the findings in another study [20]. More than half of the patients observed had hypertrophied vessels on CT images in our study, and all were HVV. Calcification was observed in some patients, moreover, all calcified lesions were observed in patients with HVV UCD, although a previous study also found calcification in PCV CD or MCD [7].

All lesions were hyperintense or isointense relative to the muscle on T1-weighted images and hyperintense or isointense on T2-weighted images. After gadolinium enhancement, all lesions demonstrated homogeneous enhancement. The MRI findings of $\mathrm{CD}$ in the present study were consistent with previous findings. DWI was performed for 6 patients and all lesions demonstrated hyperintensity on high b-value imaging; the result was similar to that of the study by Khalil et al. [21] but was higher than that reported by Oida et al. [22].

The lesions were significantly larger in patients with UCD than in those with MCD, probably because most patients with UCD had the HVV subtype, allowing for abundant blood supply. For lesion calcification, we hypothesized that the formation and type of calcification may be closely related to the histopathology of the lesion. A large number of scattered lymphoid follicles were observed in HVV lesions, and there were abundant capillaries and venous hyperplasia and vitreous degeneration in or between the follicles. In this study, the cases with calcified lesions had thickened small vessel walls with narrowing of the lumen in the central region, obvious hyaline degeneration, extensive area hardening and fibrosis, and other degenerative changes; calcium deposition occurred on the basis of these changes. Calcified lesions were distributed along the small blood vessels, and some of those micro-calcifications merged to form larger calcium deposits, which may explain the central distribution of calcification and the morphological features of branches or spots. In a previous study, dramatic enhancement during the arterial phase and decreased enhancement during the portal-venous phase was observed [16]. In addition to this pattern of enhancement on abdominal images, we also found that some lesions had a different pattern of enhancement, that is, continuous enhancement. This pattern of enhancement has not been reported 

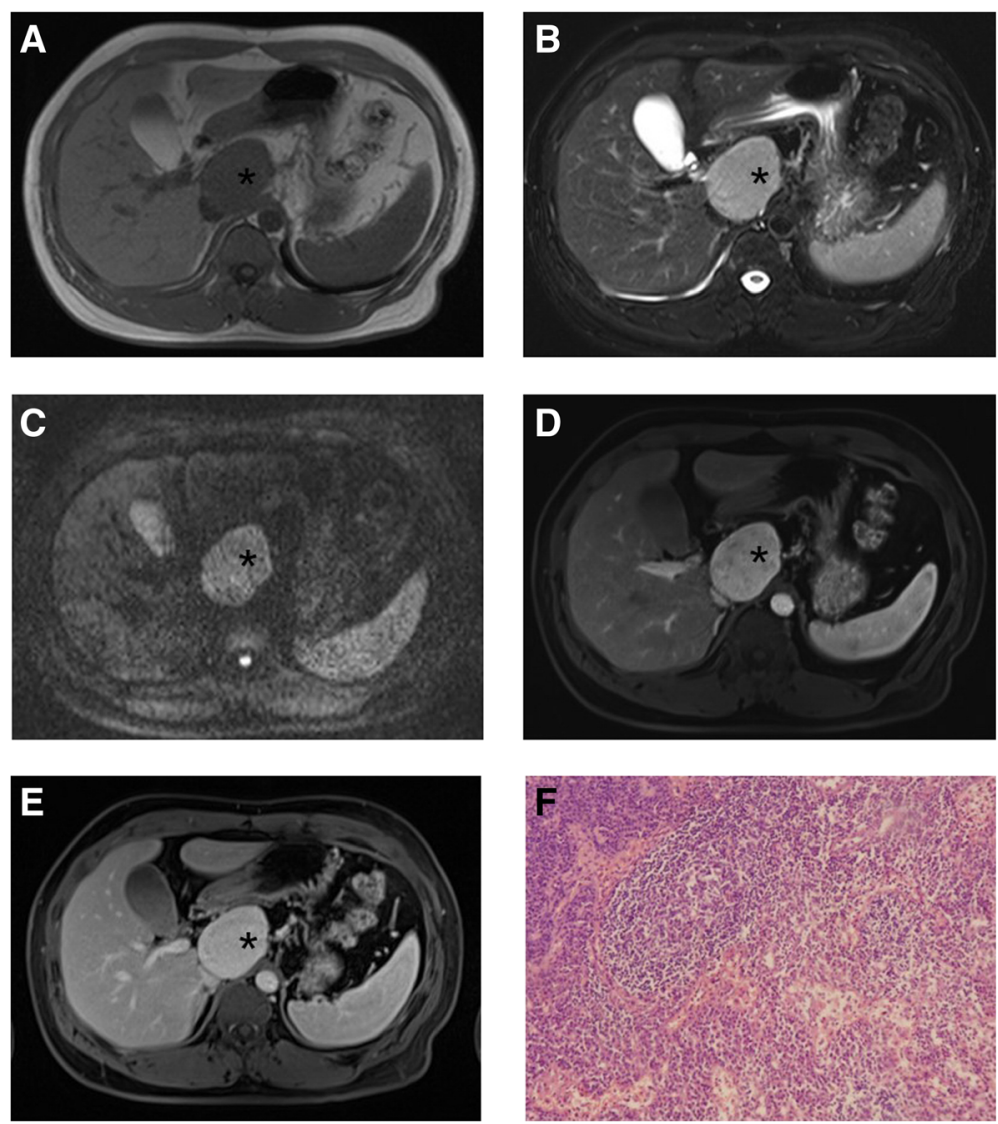

Fig. 3 A 36-year-old man with PCV unicentric Castleman disease. T1-weighted image (a) and T2-weighted image (b) show a mass $\left({ }^{*}\right)$ in the retroperitoneum, well-defined, homogeneous, hypointense on T1, hyperintense on T2 as well as on diffusion-weighted imaging (DWI) $b=600$ (c). After gadolinium contrast injection in the arterial phase (d), lesion is hyperintense, followed by sustained hyperintensity in portovenous phase (e). Photomicrograph (f, original magnification, $\times 200$; hematoxylin-eosin $[\mathrm{H}-\mathrm{E}]$ stain) shows diffuse plasma cell proliferations in the interfollicular tissue. (UCD = unicentric Castleman disease; $\mathrm{MCD}=$ multicentric Castleman disease; HW = Hyaline vascular variant; PCV = Plasma cell variant)

before. Moreover, the hypertrophied vessels of lesions were interesting and important findings. Preoperative evaluation of feeding and draining vessels around lesions is very important since the standard treatment for patients with UCD is complete surgical resection [18, 23]. Preoperative embolotherapy for hypervascular nodal vessels may facilitate uncomplicated surgical resection [24, 25].

In this study, we observed that both UCD and MCD presented some characteristic imaging features. These features may be helpful in clinical practice for the accurate diagnosis of $\mathrm{CD}$ instead of biopsy (especially since biopsy is an invasive technique, or may be difficult to conduct in some lesion locations), to assess the effects of follow-up treatment, or to assist image-guided biopsy, etc.

One limitation of our study is that HHV-8 detection tests were not performed; therefore, MCD could not be classified into its subtypes. Further, the number of patients who underwent MRI was small, and the limitation of the equipment resulted in a comparatively low b value. Lastly, although whole-body MRI plays an important role in the assessment of hematological diseases and is a good choice for MCD requiring extensive detection of lesions due to its radiation-free nature, MCD patients in our study could not undergo whole-body MRI examination as it was unavailable at our hospital. Future studies should assess the role of whole-body MRI in the diagnosis of CD.

\section{Conclusions}

In conclusion, the findings of this study suggest that the anatomic site of CD is not specific. CD often shows welldefined, mildly hypodense or isodense, homogeneous nodules or masses on non-enhanced CT/MR images, and intermediate and marked enhancement on contrast-enhanced CT/MR images. The hypertrophied vessels are valuable features. The calcification in affected lesions is not rare and is more commonly observed in HVV UCD.

In future, the differential diagnosis of UCD and other origins of single soft tissue tumors as well as the differential diagnosis of MCD and lymphoma should be investigated. 


\section{Abbreviations}

CD: Castleman disease; HHV-8: Human herpesvirus 8; HW: Hyaline vascular variant; MCD: Multicentric Castleman disease; PCV: Plasma cell variant; UCD: Unicentric Castleman disease

\section{Acknowledgements}

Not applicable.

\section{Authors' contributions}

ZS participated in its design, data acquisition and analysis, manuscript preparation; YW participated in pathological data analysis, manuscript preparation. $\mathrm{ZXH}$ collected clinical and imaging data and helped to draft the manuscript; BS and JQY put forward the concept of the study, designed the study and coordination, reviewed the manuscript. All authors have read and approved the final version of the manuscript and agree with the order of presentation of the authors.

\section{Funding}

Not applicable.

\section{Availability of data and materials}

The datasets used and/or analyzed during the current study are available from the corresponding author on reasonable request.

\section{Ethics approval and consent to participate}

All procedures performed in studies involving human participants were in accordance with the ethical standards of the institutional and/or national research committee and with the 1964 Helsinki declaration and its later amendments or comparable ethical standards. The requirement for informed consent was waived by the institutional review board.

\section{Consent for publication}

All the authors have consented to the publication of this manuscript.

\section{Competing interests}

The authors declare that they have no competing interests.

\section{Author details}

'Department of Radiology, West China Hospital, Sichuan University, No. 37, GUOXUE Alley, Chengdu 610041, China. ${ }^{2}$ Department of Pathology, West China Hospital of Sichuan University, Chengdu 610041, China.

Received: 28 May 2019 Accepted: 11 July 2019

Published online: 25 July 2019

\section{References}

1. Castleman B, Towne WW. CASE records of the Massachusetts General Hospital weekly clinicopathological exercises: case 40011. N Engl J Med. 1954;250:26-30.

2. Castleman B, Iverson L, Menendez VP. Localized mediastinal lymphnode hyperplasia resembling thymoma. Cancer. 1956;9:822-30.

3. Casper $\mathrm{C}$. The aetiology and management of Castleman disease at 50 years: translating pathophysiology to patient care. Br J Haematol. 2005;129:3-17.

4. Dispenzieri A, Armitage JO, Loe MJ, Geyer SM, Allred J, Camoriano JK, et al. The clinical spectrum of Castleman's disease. Am J Hematol. 2012;87:997-1002

5. Luo JM, Li S, Huang H, Cao J, Xu K, Bi YL, et al. Clinical spectrum of intrathoracic Castleman disease: a retrospective analysis of 48 cases in a single Chinese hospital. BMC Pulm Med. 2015;15:34.

6. Song JJ, Jung MH, Woo JS, Chae SW, Hwang SJ, Lee HM. Castleman's disease of the head and neck. Eur Arch Otorhinolaryngol. 2006;263:160-3.

7. Ko SF, Hsieh MJ, Ng SH, Lin JW, Wan YL, Lee TY, et al. Imaging spectrum of Castleman's disease. AJR Am J Roentgenol. 2004;182:769-75.

8. Frizzera G. Castleman's disease and related disorders. Semin Diagn Pathol. 1988:5:346-64

9. Johkoh T, Müller NL, Ichikado K, Nishimoto N, Yoshizaki K, Honda O, et al. Intrathoracic multicentric Castleman disease: $\mathrm{CT}$ findings in 12 patients. Radiology. 1998;209:477-81.

10. Abo-Alhassan F, Faras F, Bastaki J Al-Sihan MK Castleman disease of the parotid gland: a report of a case. Case Rep Otolaryngo. 2015;2015:265187.
11. Matsumoto T, Okuwaki K, Kida M, Jiang SX, Imaizumi H, Yamauchi H, et al. A patient with pancreatic Castleman's disease arising around the main pancreatic duct. Intern Med. 2015;54:2007-12.

12. Kligerman SJ, Auerbach A, Franks TJ, Galvin JR. Castleman disease of the thorax: clinical, radiologic, and pathologic correlation: from the radiologic pathology archives. Radiographics. 2016;36:1309-32.

13. Madan R, Chen JH, Trotman-Dickenson B, Jacobson F, Hunsaker A. The spectrum of Castleman's disease: mimics, radiologic pathologic correlation and role of imaging in patient management. Eur J Radiol. 2012;81:123-31.

14. Hill AJ, Tirumani SH, Rosenthal MH, Shinagare AB, Carrasco RD, Munshi NC, et al. Multimodality imaging and clinical features in Castleman disease: single institute experience in 30 patients. Br J Radiol. 2015;88:20140670.

15. Jiang XH, Song HM, Liu QY, Cao Y, Li GH, Zhang WD. Castleman disease of the neck: CT and MR imaging findings. Eur J Radiol. 2014;83:2041-50.

16. Gorospe L, Valdebenito-Montecino AP, Muñoz-Molina GM. Preoperative embolization of mediastinal Castleman's disease presenting with stroke. Asian Cardiovasc Thorac Ann. 2017;25:158-9.

17. Cronin DM, Warnke RA. Castleman disease: an update on classification and the spectrum of associated lesions. Adv Anat Pathol. 2009;16:236-46.

18. Ye B, Gao SG, Li W, Yang LH, Zhao SH, Ma K, et al. A retrospective study of unicentric and multicentric Castleman's disease: a report of 52 patients. Med Oncol. 2010:27:1171-8.

19. Kwon S, Lee KS, Ahn S, Song I, Kim TS. Thoracic Castleman disease: computed tomography and clinical findings. J Comput Assist Tomogr. 2013;37:1-8.

20. Bonekamp D, Horton KM, Hruban RH, Fishman EK. Castleman disease: the great mimic. Radiographics. 2011;31:1793-807.

21. Khalil G, Gaspard D, Jreige M, Nawfal G. Diffusion-weighted whole-body imaging with background body signal suppression in Castleman disease. Clin Imaging. 2013;37:185-8.

22. Oida Y, Shimizu K, Mukai M, Imaizumi T, Nakamura M, Makuuchi H. FDG-PET and diffusion-weighted MR imaging appearance in retroperitoneal Castleman's disease: a case report. Clin Imaging. 2008:32:144-6.

23. Talat N, Belgaumkar AP, Schulte KM. Surgery in Castleman's disease: a systematic review of 404 published cases. Ann Surg. 2012;255:677-84.

24. Amano Y, Takai D, Ohishi N, Shinozaki-Ushiku A, Fukayama M, Akahane M, et al. Successful treatment of mediastinal Unicentric Castleman's disease using video-assisted thoracoscopic surgery with preoperative embolization. Case Rep Med. 2013;2013:354507.

25. Aydemir B, Okay T, Imamoglu O, Sahin S, Dogusoy I. Preoperative embolization in mediastinal Castleman's disease. Thorac Cardiovasc Surg. 2010:58:496-8.

\section{Publisher's Note}

Springer Nature remains neutral with regard to jurisdictional claims in published maps and institutional affiliations.

\section{Ready to submit your research? Choose BMC and benefit from:}

- fast, convenient online submission

- thorough peer review by experienced researchers in your field

- rapid publication on acceptance

- support for research data, including large and complex data types

- gold Open Access which fosters wider collaboration and increased citations

- maximum visibility for your research: over $100 \mathrm{M}$ website views per year

At $\mathrm{BMC}$, research is always in progress.

Learn more biomedcentral.com/submission 